\title{
Single amino acid supplementation in aminoacidopathies: a systematic review
}

\author{
Danique van Vliet ${ }^{1}$, Terry GJ Derks ${ }^{1}$, Margreet van Rijn ${ }^{1}$, Martijn J de Groot ${ }^{1}$, Anita MacDonald ${ }^{2}$, \\ M Rebecca Heiner-Fokkema ${ }^{3}$ and Francjan J van Spronsen ${ }^{1 *}$
}

\begin{abstract}
Aminoacidopathies are a group of rare and diverse disorders, caused by the deficiency of an enzyme or transporter involved in amino acid metabolism. For most aminoacidopathies, dietary management is the mainstay of treatment. Such treatment includes severe natural protein restriction, combined with protein substitution with all amino acids except the amino acids prior to the metabolic block and enriched with the amino acid that has become essential by the enzymatic defect. For some aminoacidopathies, supplementation of one or two amino acids, that have not become essential by the enzymatic defect, has been suggested. This so-called single amino acid supplementation can serve different treatment objectives, but evidence is limited. The aim of the present article is to provide a systematic review on the reasons for applications of single amino acid supplementation in aminoacidopathies treated with natural protein restriction and synthetic amino acid mixtures.
\end{abstract}

Keywords: Aminoacidopathies, Inborn errors of metabolism, Single amino acid supplementation, Dietary management, Amino acid mixture, Organic acidurias

\section{Introduction}

Inborn errors of amino acid metabolism or aminoacidopathies are a group of rare and diverse disorders, in total affecting about 1 in 1000 humans worldwide [1]. These disorders can be subdivided in organic acidurias, urea cycle defects, transport defects of urea cycle intermediates, and remaining aminoacidopathies. Clinical phenotypes are highly variable, ranging from asymptomatic to lifethreatening metabolic decompensation already at neonatal age, encompassing slow deterioration of mental capacities at later age [1].

At present, dietary management is the mainstay of treatment for most aminoacidopathies. Dietary treatment aims to prevent accumulation of the substrates and associated metabolites to toxic levels, and to restore deficiencies of the enzymatic products [2]. This can be accomplished by natural protein restriction, combined with protein substitution with all amino acids except for the amino acids prior to the metabolic block and enriched with the amino

\footnotetext{
* Correspondence: f.j.van.spronsen@umcg.nl

'Department of Metabolic Diseases, Beatrix Children's Hospital, University Medical Center Groningen, University of Groningen, Groningen, the Netherlands

Full list of author information is available at the end of the article
}

acid that has become essential by the enzymatic defect $[3,4]$. Also, additional supplementation of one or two single amino acids may be required for other purposes.

This so-called single amino acid (SAA) supplementation is especially important to overcome a deficiency of the amino acid that has become essential due to the enzymatic defect. Clinically, deficiencies of specific amino acids may result in skin (hair and nail) problems, poor growth, and developmental delay [5-7]. Biochemically, such deficiencies might be detected by studying amino acid concentrations in plasma. An alternative strategy to detect amino acid deficiencies is the indicator amino acid oxidation method [8], but this method should be used for research purposes rather than for clinical practice.

The main objective of this article is to present a systematic review on SAA supplementation in aminoacidopathies. We focus on objectives other than to overcome a deficiency of the amino acid that has become essential by the enzymatic defect. Such treatment objectives include:

A. Prevention of a deficiency of a specific amino acid that has not become essential by the enzymatic defect. 
B. Prevention of toxic accumulation of specific substrates prior to the metabolic block, either by reducing synthesis or increasing excretion.

C. Competition with toxic agents for entry into target organs, especially the brain.

To our best knowledge, we identified all aminoacidopathies treated with natural protein restriction and synthetic amino acid mixtures for which additional SAA supplementation has been reported. The rationale underlying the treatment strategies and reported results were determined, while taking into account the levels of evidence.

\section{Methods}

\section{Search strategy}

We conducted a literature search on PubMed and EMBASE without date limits up to 30th of October, 2012. In PubMed, the Medical Subject Headings (MesH) terms used included ("Amino Acids/therapeutic use"[Mesh]) AND ("Amino Acid Metabolism, Inborn Errors"[Mesh] OR "Amino Acid Transport Disorders, Inborn"[Mesh] OR "Metabolism, Inborn Errors"[Mesh:NoExp]). In EMBASE, EMTREE tools used included ('amino acid'/exp/dd_dt, dd_ad,dd_ct) AND (('disorders of amino acid and protein metabolism'/exp) OR ('inborn error of metabolism'/de). The search term subheadings dd_dt, dd_ad, and dd_ct refer to drug therapy, administration and dosage, and clinical trial respectively. Additional searches were performed on 10th of June 2013 to identify possible newly added articles (published in 2012 or 2013 only) that were not yet indexed for either MesH terms or EMTREE tools. In these additional searches, (isovaleric acidemia AND glycine), (methylmalonic acidemia AND (isoleucine OR valine)), ("propionic acidemia" AND (isoleucine OR valine OR glycine)), (glutaric aciduria type 1 AND (arginine OR homoarginine OR ornithine)), (maple syrup urine disease AND (isoleucine OR valine OR norleucine)), (phenylketonuria AND (tryptophan OR threonine OR glutamine OR glutamate OR asparagine)), (tyrosinemia type 1 AND phenylalanine), (("gyrate atrophy" OR "ornithine aminotransferase deficiency") AND (lysine OR proline)), (guanidinoacetate methyltransferase deficiency AND ornithine), and (homocystinuria AND (cysteine OR cystine OR arginine)) were entered as free text for both databases. Language limits for all searches were set at English and German.

\section{Study selection}

First, titles and/or abstracts of all identified non-duplicate references were screened to select eligible studies. Eligibility criteria included: 1) involving an aminoacidopathy which is treated (among else) with natural protein restriction and a synthetic amino acid mixture; 2) possibly referring to SAA supplementation. Then, full-text articles of the selected references were retrieved and read independently to assess whether the inclusion criteria were met. Inclusion criteria were: 1) SAA treatment regimens are clearly defined; 2) SAA treatment effects are clearly defined. Articles only addressing the application of SAA supplementation to restore the concentrations of the amino acid that has become essential by the enzymatic defect were excluded, as were abstracts and conference proceedings, and research performed in animal models that are not based on a genetic defect. The reference lists of all full-read articles were reviewed to identify additional eligible studies. Results of the reviewing process are outlined in Figure 1.

\section{Results}

Table 1 presents an overview of all relevant aminoacidopathies for which SAA supplementation has been described, including the treatment strategy and the level of evidence. This table includes only the aminoacidopathies for which severe natural protein restriction and an amino acid mixture devoid of the offending precursor amino acids or an essential amino acid supplement is a generally accepted treatment. More detailed information about the results of SAA supplementation in these aminoacidopathies can be found in Additional file 1. In addition, three aminoacidopathies (hyperammonaemia-hyperornithinaemia-homocitrullinuria syndrome, lysinuric protein intolerance, and nonketotic hyperglycinemia), for which combined natural protein restriction and an essential amino acid mixture is more controversial, are worth discussion with respect to SAA supplementation. We will now continue by addressing these SAA supplementation regimens for each aminoacidopathy individually.

\section{Isovaleric acidemia}

Isovaleric acidemia (McKusick 243500) is an inherited defect of leucine catabolism, caused by isovaleryl-CoA dehydrogenase deficiency. This deficiency results in the accumulation of isovaleryl-CoA and its metabolites, including isovaleric acid (IVA). Under stable conditions, detoxification proceeds by alternate pathways in glycine- and carnitine conjugates, including $\mathrm{N}$-isovalerylglycine (IVG), which can be easily excreted by the kidneys. However, after protein intake and/or periods of catabolism [9], capacity of this alternative pathway detoxification does not suffice. This results in ketoacidosis or, sometimes, even in coma.

In the case of glycine supplementation treatment, leucine-loading tests showed higher urinary excretion of IVG [10-12] and related metabolites [11,12], less increased plasma IVA concentrations $[10,11,13]$, and no vomiting [10]. In the case of acute metabolic decompensation, often precipitated by illness, glycine supplementation has been described to result in a decline of plasma IVA concentrations, concomitant with an increase in urinary IVG 


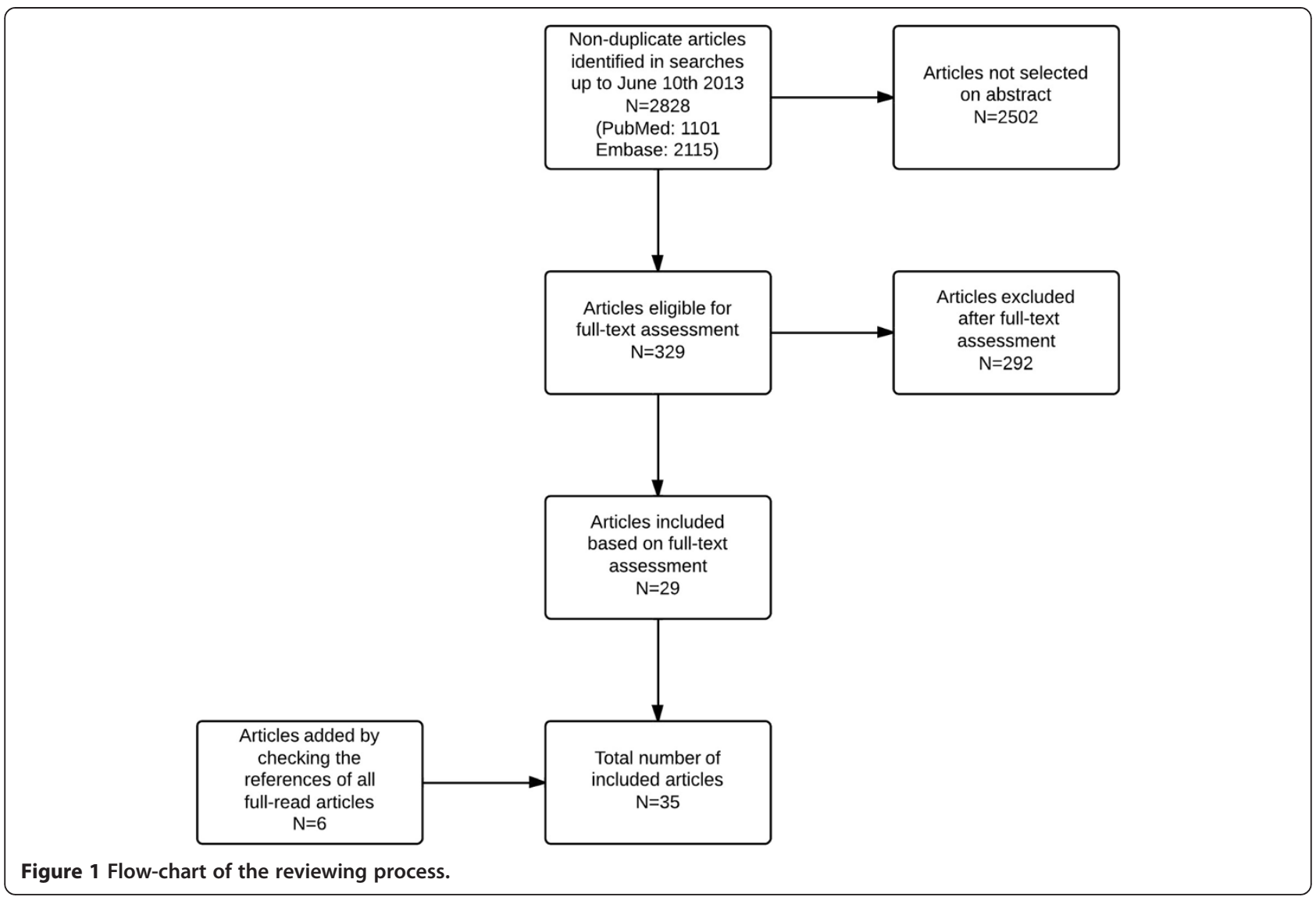

excretion [13-15], followed by a neurological and haematological response after one to two weeks of treatment $[14,15]$.

As episodes of metabolic decompensation are difficult to predict, chronic management with glycine to prevent such episodes has been investigated [16-20]. Several studies support lower doses for maintenance treatment than for acute management, in order to prevent side-effects due to hyperglycinemia [16-18]. At oral dosages of $300 \mathrm{mg} / \mathrm{kg} / \mathrm{d}$, plasma glycine concentrations up to $1680 \mu \mathrm{M}$ have been observed, concomitant with increased lethargy and ataxia $[17,18]$. In contrast, Naglak et. al. (1988) did not report on any encephalopathic side-effects of glycine dosed at $600 \mathrm{mg} / \mathrm{kg}$ under constant leucine restriction, although plasma glycine concentrations at this dosage even reached $2547 \pm 591 \mu \mathrm{M}$ [16]. Alternatively, to circumvent possible encephalopathic side-effects or to increase treatment effectiveness, carnitine administration has been proposed either as monotherapy or in addition to glycine supplementation [12,17-20]. However, considering the scope of the present review, evidence on carnitine supplementation in isovaleric acidemia is not discussed in further detail. To conclude, glycine supplementation has been shown to be effective both in acute and chronic management of individual IVA patients (level
4-5), but encephalopathic side-effects have been reported at plasma glycine concentrations $>1000 \mu \mathrm{M}$.

\section{Methylmalonic acidemia}

Methylmalonic acidemia (MMA; McKusick 251000) is caused by methylmalonyl-CoA mutase deficiency. To reduce accumulation of methylmalonyl-CoA and associated metabolites, dietary restriction of precursor amino acids (valine, isoleucine, methionine, and threonine) and sometimes also odd-chain fatty acids is used. In addition, fasting should be avoided to prevent endogenous catabolism. Under this treatment regimen, some patients suffered from severe acrodermatitis enteropathica like skin lesions (despite adequate blood zinc concentrations) which, in some cases, even culminated in sepsis and death [21]. Especially isoleucine deficiency has been associated with these skin lesions [6,22-24]. In MMA patients on dietary treatment, isoleucine and valine deficiencies are regularly observed [25].

SAA supplementation with isoleucine $(48-340 \mathrm{mg} / \mathrm{d})$ and valine $(68-170 \mathrm{mg} / \mathrm{d})$ to prevent essential amino acid deficiencies and associated skin lesions has become routine clinical practice in some centers without any reported adverse effects [26]. Still, defining optimal dietary 
Table 1 Suggested applications of SAA supplements in different aminoacidopathies

\begin{tabular}{|c|c|c|c|c|c|}
\hline \multirow[t]{2}{*}{ Disorder } & \multicolumn{3}{|c|}{ Treatment objective } & \multicolumn{2}{|c|}{ Level of evidence } \\
\hline & A & B & C & & \\
\hline IVA & & Glycine & & $4-5$ & \\
\hline MMA & Isoleucine + Valine & & & 5 & \\
\hline \multirow[t]{2}{*}{ PA } & & Glycine & & 5 & \\
\hline & Isoleucine + Valine & & & 5 & \\
\hline \multirow[t]{3}{*}{ GA-I } & & & Arginine & $3 b$ & animal \\
\hline & & & Homoarginine & - & animal \\
\hline & & & Ornithine & - & animal \\
\hline \multirow[t]{3}{*}{ MSUD } & & & Isoleucine + Valine & - & \\
\hline & & & Norleucine & - & animal \\
\hline & Isoleucine + Valine & & & $4-5$ & \\
\hline \multirow[t]{10}{*}{ PKU } & & Glutamine & & 5 & \\
\hline & & Glutamate & & 5 & \\
\hline & & Asparagine & & 5 & \\
\hline & & Threonine & & $3 b$ & \\
\hline & & & MAIB & - & animal \\
\hline & & & AIB & - & animal \\
\hline & & & NB & - & animal \\
\hline & & & Norleucine & - & animal \\
\hline & Tryptophan & & & 4 & \\
\hline & Glutamine & & & 4 & \\
\hline HT1 & Phenylalanine & & & 4 & \\
\hline \multirow[t]{2}{*}{ OAT deficiency } & & Lysine & & 4 & \\
\hline & Proline & & & 4 & \\
\hline GAMT deficiency & & Ornithine & Ornithine & 5 & \\
\hline \multirow[t]{3}{*}{$\mathrm{HCU}$} & & & Arginine & 5 & \\
\hline & & Cysteine & & - & \\
\hline & Arginine* & Arginine* & Arginine* & $1 b$ & \\
\hline
\end{tabular}

Therapeutic objective A) correction of amino acid deficiency; B) prevention of toxic accumulation of specific substrates prior to the metabolic block; C) competition with toxic agents for entry into target organs

MAIB: N-methyl-aminoisobutyrate; AIB: 2-aminoisobutyrate; NB: 2-aminonorbornane

*Treatment objective is unclear.

treatment is very difficult [27], exemplified by the fact that not only metabolic crises still occur if offending precursor amino acids are elevated due to endogenous catabolism, but offending precursor amino acids can become overly restricted as well. To conclude, additional isoleucine and valine supplementation to prevent deficiencies in MMA patients has become routine clinical practice in some centers. Currently, the level of evidence is 5. So far, its effects and possible side-effects have not been investigated.

\section{Propionic acidemia}

Propionic acidemia (PA; McKusick 232000) is characterized by propionyl-CoA carboxylase deficiency, blocking the BCAA catabolic pathway one step earlier than in
MMA. Dietary treatment is very similar to that used in MMA, with restriction of natural protein and sometimes also odd-chain fatty acids, as well as supplementation of a synthetic amino acid mixture devoid of valine, isoleucine, methionine, and threonine being reported. In addition, fasting should be avoided. In the past, it has been incorrectly assumed that leucine should be restricted as well, leading to growth restriction without any benefit on PA symptomatology [28].

As in other inborn errors of amino acid metabolism, various SAA supplementation treatment strategies have been proposed. The most widely suggested one is the use of isoleucine and valine supplementation, comparable with the application described for MMA [29]. As in MMA, deficiencies of both isoleucine and valine are 
often observed [25,30]. In addition, Scholl-Bürgi et al. showed that blood isoleucine and valine concentrations, in contrast to almost all other amino acids, did not correlate with age [31]. To prevent a relative isoleucine deficiency, the use of routine isoleucine supplementation (100 mg/d) has been reported [32].

A different SAA treatment includes supplementation of glycine to promote conjugation of propionyl CoA and tiglyl CoA, and thereby to stimulate urinary excretion. This may seem contra intuitive, as hyperglycinaemia is observed in nearly all PA patients [30]. Blood glycine concentrations in PA patients, however, have been found to correlate with blood bicarbonate concentrations [33]. Furthermore, the affinity of propionate to conjugate with either glycine or carnitine has been hypothesized to be $\mathrm{pH}$-sensitive, glycine being favoured during periods of ketoacidosis. Although urinary excretion of propionylglycine and tiglylglycine indeed increased on glycine supplementation (two doses of $200 \mathrm{mg} / \mathrm{kg}$ ), this was complicated by arterial hyperammonemia [34]. It was therefore concluded that glycine supplementation was not desirable for PA management. However, it could well be that the arterial hyperammonemia was due to the increased nitrogen load rather than the glycine supplementation itself, as protein intake had been restricted earlier to $0.9 \mathrm{~g} / \mathrm{kg} /$ day for $1.0 \mathrm{~g} / \mathrm{kg} /$ day was not tolerated. To conclude, the effect of isoleucine and valine supplementation in PA management has not been investigated, although preventive isoleucine supplementation is currently applied in some centers (level 5). Glycine supplementation clearly was not effective (level 5).

\section{Glutaric aciduria type I}

Glutaric aciduria type I (GA-I; McKusick 231670) is caused by glutaryl-CoA dehydrogenase deficiency, which is required for lysine and tryptophan oxidation. Especially, elevated brain concentrations of glutaric acid, due to increased cerebral lysine catabolism, correlate with GA-I symptomatology: acute encephalopathic crises, often typically precipitated by mild infections. Current management includes a protein restricted diet with a lysine-free and low-tryptophan amino acid mixture, and carnitine administration [35].

To reduce brain lysine concentrations even further without inducing non-brain lysine deficiencies, supplementation of substrates competing with lysine for brain uptake by the $y+$ transporter has been suggested as an additional treatment modality [36-38]. Indeed, homoarginine (a homologue of L-arginine, synthesized from lysine) or arginine supplementation in a GA-I mouse model showed promising results, whereas ornithine supplementation resulted in increased mortality rates, similar to high-protein diet exposure [39]. Administration of homoarginine reduced brain lysine and glutaric acid accumulation, and increased survival in a GA-I mouse model [40]. In addition, arginine supplementation decreased glutaric acid and 3-hydroxyglutaric acid concentrations in both brain and liver. As system $\mathrm{y}^{+}$transport is only expressed at the $\mathrm{BBB}$, the inhibition of hepatic metabolite accumulation by arginine supplementation is possibly mediated by a different transport mechanism. Reduced lysine concentrations in cerebral and hepatic mitochondria of GA-I mice receiving arginine supplementation are indicative of the fact that the human mitochondrial ornithine carrier 1 might be such a mediating transporter [41].

In GA-I patients, administration of an argininefortified amino acid supplement biochemically resulted in reduced plasma lysine concentrations and urinary 3hydroxyglutarate excretion, compared to historical data on GA-I patients receiving conventional lysine restricted dietary regimens. This was accompanied by reduced calculated brain lysine, and increased calculated brain arginine influx. However, arginine fortification did not improve growth [42]. In patients receiving either one of two amino acid supplements, fortified with different amounts of arginine, no significant correlations were found between arginine intake and plasma lysine-toarginine ratios or neurological outcome [43].

Recommendations for arginine fortification in both chronic and outpatient sick-day management have been established based on aforementioned studies. In chronic management, dietary intake of lysine and arginine of 65-85 mg/kg/day and 100-150 mg/kg/day are suggested, aiming at a ratio of dietary lysine/arginine intake of 0.5 0.8 . For outpatient sick-day management, recommended dietary lysine intake is even lower $(30-35 \mathrm{mg} / \mathrm{kg} /$ day), whereas recommended dietary arginine intake is even higher aiming at a dietary lysine/arginine intake of 0.150.20 (mg:mg) [42]. To conclude, homoarginine and arginine supplementation decreased brain lysine and glutaric acid concentrations in a GA-I mouse model. In patients, arginine fortification showed reduced calculated brain lysine (level 3b), but no clinical improvement (level 3b), and the effect on actual brain lysine and glutaric acid concentrations still needs to be investigated.

\section{Maple syrup urine disease}

Maple syrup urine disease (MSUD; McKusick 231670) is an inherited defect in BCAA catabolism caused by deficient branched-chain $\alpha$-ketoacid dehydrogenase. Although all BCAA accumulate, leucine accumulation is considered to be particularly toxic and associated with cerebral manifestations. Episodes of metabolic decompensation mainly occur by endogenous protein catabolism, as observed in normal postpartum state of neonates or precipitated by mild infections or physiologic stress in older patients. Dietary management aims to restrict BCAA intake and to 
prevent endogenous protein catabolism. Classically, MSUD amino acid formula was thus designed to contain no BCAA. However, limited and strongly regulated supplementation of isoleucine and valine has been suggested both in chronic and acute dietary management [44].

By indicator amino acid oxidation measurement, Riazi et al. estimated the mean total BCAA requirement for MSUD patients to be $45 \mathrm{mg} / \mathrm{kg} / \mathrm{d}$ (leucine $17.3 \mathrm{mg} / \mathrm{kg} / \mathrm{d}$; isoleucine $14.6 \mathrm{mg} / \mathrm{kg} / \mathrm{d}$; and valine $13.1 \mathrm{mg} / \mathrm{kg} / \mathrm{d}$ ) [45]. Especially chronic deficiency of isoleucine may result in acrodermatitis enteropathica-like skin eruptions [46-48]. At present, no acrodermatitis enteropathica-like syndromes have been reported in centers in which supplementation of isoleucine and valine as well as regular monitoring of blood BCAA concentrations has become routine clinical practice $[44,49]$.

During episodes of acute metabolic decompensation, supplementation of isoleucine and valine could serve other treatment strategies. First, isoleucine and valine may become limited factors for protein synthesis, thereby inducing increased blood leucine concentrations due to increased proteolysis. To prevent this, supplementation of isoleucine and valine has been suggested [50,51]. Second, supplementation of isoleucine and valine has been suggested to compete with leucine for brain uptake and thereby to counteract the encephalopathic effects of excessive brain leucine accumulation [44]. Such a mechanism has been shown for the non-physiological amino acid norleucine in an animal model of MSUD [52,53].

Recent management guidelines offer special attention to isoleucine and valine supplementation in both chronic and acute management $[44,49]$ and emphasize on regular monitoring of BCAA in blood. In chronic management, supplementation of isoleucine and valine should be targeted at blood molar ratios of leucine/isoleucine $=2$ and leucine/ valine $\geq 0.5$ respectively. To maintain these ratios, mean valine supplementation has been found to decrease during the first 3 years of life $(11.5 \mathrm{mg} / \mathrm{kg} / \mathrm{d}$ to $5.8 \mathrm{mg} / \mathrm{kg} / \mathrm{d})$, whereas mean isoleucine supplementation remained relatively stable $(4.4 \mathrm{mg} / \mathrm{kg} / \mathrm{d}$ to $5.5 \mathrm{mg} / \mathrm{kg} / \mathrm{d})$ [49]. During outpatient catabolic management, isoleucine and valine supplementation should be increased to $15-30 \mathrm{mg} / \mathrm{kg} / \mathrm{d}$, whereas inpatient catabolic management should include IV administration of isoleucine and valine at $20-120 \mathrm{mg} / \mathrm{kg} / \mathrm{d}$ [49]. However, IV single valine and isoleucine solutions are not available in every country for use with MSUD patients. Research in MSUD patients, rats, and MSUD cell models showed that, of all BCAA, leucine is most toxic to the brain [54-56]. Nonetheless, cerebral toxicity from (chronically) elevated blood isoleucine and/or valine concentrations cannot be excluded based on the evidence currently available, and safe upper limits for blood isoleucine and valine have not yet been established. To conclude, isoleucine and valine supplementation in MSUD patients resolved dermatitis (level 4-5), but preventive treatment has not been studied. Moreover, isoleucine and valine supplementation during acute metabolic decompensation decreased blood leucine concentrations (level 5), whereas the effect on brain leucine concentrations still remains to be investigated.

\section{Phenylketonuria}

Phenylketonuria (PKU; McKusick 261600) is caused by deficiency of phenylalanine hydroxylase, resulting in excessively elevated blood phenylalanine concentrations and normal to slightly decreased blood tyrosine concentrations. Especially the elevated blood phenylalanine concentrations have been associated with PKU symptomatology, including severe mental retardation, developmental delay, seizures, and psychiatric problems. Dietary management includes restriction of natural protein and a phenylalanine-free amino acid supplement. Although early initiation of this diet has abolished development of severe mental retardation and epilepsy, mild cognitive impairments as well as neuropsychological deficits still occur. Besides additional supplementation of tyrosine, different alternative SAA treatments have been reported. Apart from the very early but unsuccessful ideas about glutamine supplementation [57-59], the following suggestions on SAA supplementation have been proposed.

Threonine supplementation has been suggested to decrease blood phenylalanine concentrations. This concept was based on the observations that blood threonine concentrations were inversely related to blood phenylalanine concentrations in PKU patients [60] and that threonine administration in rats decreased blood phenylalanine concentrations exclusively [61]. Indeed, threonine supplementation $(50 \mathrm{mg} / \mathrm{kg} / \mathrm{d}$; approximately $60 \%$ of unsupplemented threonine intake) in PKU patients reduced both blood phenylalanine concentrations as well as urinary phenylalanine excretion [62], possibly due to competition with phenylalanine for facilitated transport at the gut-blood barrier [63].

In the 1970s, tryptophan supplementation has been proposed to restore a possible tryptophan deficiency in brain. The experimental data originate from a rat model treated with phenylalanine and the phenylalanine hydroxylase inhibitor dl-p-chlorophenylalanine [64]. In this pharmacological model, tryptophan supplementation partly corrected impairments in the swim maze and of conditioned shock avoidance as well as decreased brain serotonin and 5hydroxyindoleacetic acid concentrations. However, this rat model is now considered invalid to reflect PKU, as dl-pchlorophenylalanine also inhibits tryptophan hydroxylase [65]. In two late-diagnosed PKU patients, supplementation of tryptophan $(100 \mathrm{mg} / \mathrm{kg} / \mathrm{d})$ has been reported to increase serotonin metabolite concentrations in cerebrospinal fluid without influencing blood phenylalanine concentrations. 
Also, increased vigilance was observed in the one patient that showed abnormal vigilance when untreated [66].

Recently, administration of 2-aminoisobutyrate and nonphysiological amino acids such as DL-norleucine, 2aminonorbornane, and N-methyl-aminoisobutyrate acting as inhibitors for various brain amino acid transporters have been shown to reduce brain phenylalanine concentrations up to 56\% in PKU mice [67]. To conclude, threonine supplementation in PKU patients decreased blood phenylalanine concentrations in a single study (level $3 b$ ), while tryptophan supplementation seemed to have a positive effect in two late-diagnosed and untreated patients (level 4).

\section{Tyrosinemia type I}

Hereditary tyrosinemia type I (HT1; McKusick 276600) is caused by a deficiency of fumarylacetoacetase. This enzyme is responsible for the conversion of fumarylacetoacetate to fumarate and acetoacetate, the last step in tyrosine catabolism. Untreated, the enzymatic block results in accumulation of extremely toxic metabolites (including maleylacetoacetate, fumarylacetoacetate, succinylacetoacetate, and succinylacetone) causing liver damage. As a consequence of the liver damage, markedly elevated blood tyrosine (phenylalanine and methionine) concentrations occur. The principal treatment is the administration of 2-(2-nitro-4-trifluoromethylbenzyl)-1,3cyclohexanedione (NTBC) to prevent accumulation of these toxic tyrosine metabolites by inhibiting tyrosine catabolism at an earlier step. Additional dietary management includes natural protein restriction supplemented with an amino acid mixture devoid of tyrosine as well as phenylalanine, as $27-41 \%$ of phenylalanine has been shown to be converted to tyrosine in the first 5-8 hours after intake $[68,69]$. Targeting the complications of this treatment regimen, two different types of single amino acid supplementation have been described.

Firstly, phenylalanine supplementation has been suggested to restore its potential deficiency [70]. With dietary restriction of both tyrosine and phenylalanine, very low blood phenylalanine concentrations have been reported [70,71], that may be improved by supplementing with additional phenylalanine [70]. Concerns have been raised that phenylalanine deficiency in HT1 would limit protein synthesis, and thereby impair cognitive outcome and growth $[70,71]$. However, no data are available on the safe lower limits of blood phenylalanine concentrations, which, theoretically, can be an age-dependent parameter, related to maintenance of protein synthesis to facilitate (brain) development and growth. On the other hand, phenylalanine supplementation may limit natural tyrosine tolerance by increased conversion of phenylalanine to tyrosine.

Secondly, in rats, threonine supplementation has been shown to partly prevent the ocular lesions caused by tyrosine toxicity [72-75]. Although the underlying mechanism is still unknown, it has been suggested that blood tyrosine concentrations decrease if tyrosine administration is combined with threonine [73,74]. Therefore, it can be hypothesized that threonine could protect against ocular lesions by lowering blood tyrosine concentrations either by competition with tyrosine and/or phenylalanine for uptake at the gut-blood barrier or in the renal tubules, or by promoting tyrosine oxidation in the liver [75]. However, as threonine supplementation has also been shown to partly prevent ocular lesions with NTBC administration without reducing blood tyrosine concentrations, the positive effects of threonine do not seem to be solely due to a reduction of hypertyrosinemia [75]. To conclude, additional phenylalanine supplementation in HT1 patients clearly increased the otherwise very low blood phenylalanine concentrations (level 4), but the possible clinical effects remain to be investigated. Moreover, threonine supplementation showed positive effects in hypertyrosinemic rats on ocular lesions, but no clinical studies have been conducted yet.

\section{Ornithine aminotransferase deficiency}

Ornithine aminotransferase (OAT) deficiency or gyrate atrophy (GA; McKusick 258870) is an inherited deficiency of ornithine aminotransferase. Using pyridoxal-phosphate as a cofactor, the enzyme is responsible for the reversible conversion of ornithine and $\alpha$-ketoglutarate to pyrroline5 -carboxylate and glutamate. Clinically, GA is mostly characterized by a slowly progressive loss of vision, culminating in blindness by the fifth decade of life. However, a neonatal presentation with acute hyperammonemia is also recognized [76]. Biochemically, the enzyme deficiency results in 10-20 times elevated blood ornithine concentrations. Although some patients respond to pyridoxine administration, the cornerstone of treatment is an arginine restricted diet. In practice, this treatment includes restriction of natural protein with supplementation of a synthetic amino acid mixture devoid of arginine.

Different SAA supplementation regimens have been investigated for OAT deficiency. Firstly, lysine supplementation $(10-15 \mathrm{~g} / \mathrm{d})$ has been shown to decrease blood ornithine concentrations by increasing its urinary excretion $[77,78]$. This is probably due to the fact that ornithine and arginine share a common renal transport system with lysine and cyst(e)ine. Whether this treatment could slow or prevent loss of vision, or could increase protein tolerance, has not been investigated.

Secondly, proline supplementation has been hypothesized to restore a proline deficiency $[79,80]$. Ornithine catabolism is considered important for proline synthesis especially in the retinal pigment epithelium, where OAT activity is ten times higher compared to the liver [81]. Moreover, oral ornithine loading in GA patients could 
not increase blood proline concentrations as in normal subjects, suggesting that proline indeed becomes an essential amino acid in GA [80]. In an in vitro model of human retinal pigment epithelial cells, administration of proline could prevent the cytotoxic effects of OAT deficiency [82]. In GA patients, proline supplementation was found to minimize chorioretinal deterioration (in 3 of 4 patients) and even improve vision in 1 patient [79]. To conclude, lysine supplementation in GA patients reduced blood ornithine concentrations by increasing its urinary excretion (level 4), and proline supplementation seemed to have a positive effect on vision (level 4). However, further evidence is required.

\section{Guanidinoacetate methyltransferase deficiency}

Guanidinoacetate methyltransferase (GAMT; McKusick 601240) deficiency is an inherited disorder of creatine synthesis. Clinically, untreated GAMT deficiency mainly results in expressive language impairments, extrapyramidal movements, epilepsy, autistic and self-injurious behaviour, and developmental delay. Biochemically, the enzymatic block prevents creatine to be synthesized from guanidinoacetate (GAA). Hence, the disorder is characterized by accumulation of GAA and deficiency of creatine. Treatment includes creatine supplementation in order to restore cerebral creatine levels [83]. GAA is considered to be toxic. To prevent accumulation, arginine restriction, administration of sodium benzoate, and ornithine supplementation have been proposed [84-86].

Arginine (combined with glycine) is the precursor of GAA. Ornithine may decrease the conversion of arginine to GAA [85] and reduce tubular arginine reabsorption, as both amino acids use the same dibasic amino acid transporter [87], while sodium benzoate removes glycine. Combined arginine restriction and ornithine supplementation (100 and $400 \mathrm{mg} / \mathrm{kg} / \mathrm{d}$ ) has been reported to decrease blood arginine as well as GAA concentrations $[86,88]$. Decreased arginine intake without ornithine supplementation does not have that effect [84]. Additional ornithine supplementation has been hypothesized to enhance the GAA lowering effect of dietary arginine restriction [86]. The exact ornithine dose needed may probably be between 600 and $800 \mathrm{mg} / \mathrm{kg} / \mathrm{d}$ [83,89]. To conclude, ornithine supplementation in combination with arginine restriction may be helpful in decreasing blood arginine concentrations in GAMT deficiency patients (level 5).

\section{Homocystinuria}

Homocystinuria (HCU; McKusick 263200) is an inherited deficiency of cystathionine $\beta$-synthase (CBS). Using pyridoxal-phosphate as a cofactor, the enzyme is involved in the transsulfuration of homocysteine to form cystathionine. Biochemically, $\mathrm{HCU}$ is primarily characterized by increased blood homocysteine and methionine concentrations. The elevated homocysteine concentrations are associated with clinical features, including ectopia lentis, mental retardation, dental anomalies, osteoporosis, behavioral problems, and arachnodactyly. Some patients respond very well to pyridoxine treatment. If not, dietary management is indicated including natural protein restriction, an amino acid mixture devoid of methionine, and supplementation of folate. In addition, different SAA supplementation regimens have been proposed.

In daily practice, cysteine is added to all L-amino acid supplements (30-50 mg of cysteine per $\mathrm{g}$ of protein equivalent). Besides restoring a deficiency of this amino acid, cysteine has been hypothesized to reduce blood homocysteine concentrations. However, to the best of our knowledge, no study has investigated the possible homocysteine-lowering effect of cysteine supplementation in CBS-deficient patients. Four main theories have been postulated for the possible mechanisms underlying this effect. As summarized by Kawakami et al., cysteine may 1) remove homocysteine from its protein-bound form to a low-molecular weight form, facilitating increased urinary clearance; 2) decrease homocysteine formation from methionine; and 3) increase remethylation of homocysteine to form methionine [90]. In support of the first hypothesis, cysteine has been shown to decrease the percentage of homocysteine bound to protein as well as the total homocysteine concentration in rats [90]. Both effects were only observed in rats fed a low protein and low methionine diet [90]. In contrast to the first hypothesis, a fourth hypothesis states that additional cysteine supplementation (in case of total blood cysteine concentrations $<170 \mu \mathrm{mol} / \mathrm{L})$ may reduce free plasma homocysteine concentrations [91]. In HCU patients with blood cystine concentrations $<170 \mu \mathrm{mol} / \mathrm{L}$, the homocysteine free/bound ratio was found to increase, possibly to maintain the total aminothiol free/bound ratio (thiol redox) at a constant level. Normally, this thiol redox is determined by the ratio of free/bound cysteine and is kept relatively constant [91].

Arginine has been proposed to be supplemented for two reasons: 1) to decrease endothelial dysfunction [92], and 2) to compete with renal homocysteine reabsorption [93]. Although the exact mechanism of vascular damage in $\mathrm{HCU}$ is not well understood, reduced nitrogen oxide (NO) probably plays a central role and increased concentrations of asymmetric dimethylarginine (ADMA), an endogenous NO synthase inhibitor, have been found. Arginine supplementation could counteract the effects of elevated ADMA concentrations [92]. Regarding its second treatment objective, arginine glutamate infusion has been reported to markedly increase urinary homocysteine and homocysteine-cysteine disulphide excretion. However, blood homocysteine concentrations remained 
unchanged, whereas blood cysteine, lysine, arginine, and ornithine concentrations increased [93]. To conclude, besides the restoration of a cysteine deficiency, cysteine supplementation in HCU patients may have additional effects that should be investigated. Moreover, arginine supplementation has been found to decrease endothelial dysfunction (level $1 \mathrm{~b}$ ), but the underlying mechanism is not fully understood.

\section{Hyperammonaemia-hyperornithinaemia-homocitrullinuria syndrome}

Hyperammonaemia-hyperornithinaemia-homocitrullinuria (HHH; McKusick 238970) syndrome is an inherited defect of the ornithine transporter 1 located on the inner mitochondrial membrane. This transporter facilitates ornithine influx and citrulline efflux. Accordingly, the defect underlying $\mathrm{HHH}$ syndrome results in cytosolic ornithine accumulation and intramitochondrial ornithine deficiency as well as citrulline accumulation. Protein restriction is the main treatment. In some centers, an essential amino acid mixture, designed for urea cycle disorders, is prescribed according to clinical tolerance. A variety of SAA supplementation regimens have been investigated, including the amino acids ornithine, arginine, citrulline, lysine, and proline in $\mathrm{HHH}$ syndrome [94-98].

Supplementation with ornithine has been suggested, but ornithine hydrochloride rather than ornithine supplementation seems to result in a decrease of blood ammonia concentrations [94-96], while long-term (exceeding a few years) or high-dose (inducing blood concentrations exceeding $600 \mu \mathrm{mol} / \mathrm{L}$ ) ornithine has been associated with retinal toxicity [97].

A study comparing the effects of ornithine, arginine or citrulline supplementation in two $\mathrm{HHH}$ patients suggested that citrulline is probably the best SAA to supplement for chronic $\mathrm{HHH}$ management $[96,98]$, but a low protein diet only could be more important for chronic management. Supplementation of SAA would then be reserved for periods of metabolic decompensation [96]. Lysine or proline supplementation has also been proposed for $\mathrm{HHH}$ treatment, but the rationale for these hypothesized SAA treatments has not been fully defined. Neither lysine nor proline has been shown to be beneficial [96]. To conclude, of all SAA supplementation regimens investigated in $\mathrm{HHH}$ patients, citrulline supplementation was found to be most effective (level 4), but such supplementation should probably be reserved for periods of acute metabolic decompensation only.

\section{Lysinuric protein intolerance}

Lysinuric protein intolerance (LPI; McKusick 222700) is an inherited defect in the $\mathrm{y}^{+} \mathrm{LAT} 1$ transporter, involved in the transport of the dibasic amino acids lysine, arginine, and ornithine in the intestine, kidney, and liver.
Most patients develop a strong protein aversion. Incidental protein intake characteristically results in hyperammonemia, caused by a secondary dysfunction of the urea cycle due to arginine and ornithine deficiency. Additional clinical manifestations include growth retardation, osteoporosis, hepatosplenomegaly, pulmonary alveolar proteinosis, renal involvement, and hematological abnormalities. Biochemically, LPI is mainly characterized by markedly increased urinary arginine, ornithine, and lysine excretion and thereby reduced concentrations of these amino acids in blood. The mainstay of treatment includes natural protein restriction to prevent hyperammonemia, while also providing sufficient essential amino acids to maintain normal development and growth. To this purpose, sometimes, an essential amino acid mixture is added as in HHH [99]. Since the first description of LPI in 1965, different approaches on additional SAA supplementations have been suggested [100-112].

The most common approach is citrulline supplementation $(0.5-1.1 \mathrm{mmol} / \mathrm{kg} / \mathrm{d})$, for which the rationale is to restore urea cycle functioning [100-102]. Clinically, longterm citrulline supplementation diminishes protein aversion $[101,103,104]$, increases growth rate [101,103,104], improves hair quality [103,104], and diminishes centripetal obesity as well as folliculitis [103], while the effect on bone mineral density remains controversial $[103,104]$. Effects on hepatomegaly and hematological as well as immunological parameters are not evident [101,104].

Lysine supplementation restores lysine deficiency [104,108-110], but, unfortunately, long-term lysine supplementation failed to improve growth and to reduce infection frequency $[104,110]$. At high dosage $(0.8-1.2 \mathrm{~g} / \mathrm{kg} / \mathrm{d})$, lysine supplementation even induced gastrointestinal sideeffects as abdominal cramps and diarrhoea [104,108]. Supplementation with homocitrulline to restore the lysine was unsuccessful [111].

Although arginine and ornithine supplementation were shown to prevent hyperammonemia [101,102,105,112], and to stimulate urea formation $[101,105]$, long-term treatment effects remained inconclusive [101,105-107]. Various studies comparing different (combinations of) SAA supplementation regimens have not provided the optimal regimen for LPI [100,102,104,107], although all advise positively on citrulline. To conclude, long-term citrulline supplementation resulted in clinical improvement of LPI patients (level 4). The effect of other SAA supplementation regimens, especially on the long-term, is still unclear.

\section{Nonketotic hyperglycinemia}

Nonketotic hyperglycinemia (NKH; McKusick 238300, 238310, and 238330) is characterized by a defective glycine cleavage system, resulting in excessive glycine concentrations in both blood and brain. The role of glycine as an excitatory agonist of the NMDA receptor in the 
cortex, and as an inhibitory neurotransmitter in the brain stem and spinal cord, may well explain NKH symptomatology, which is characterized primarily by intractable seizures and progressive brain damage. A glycinerestricted diet has been tried as well as benzoate and NMDA receptor antagonists, but without any clinical improvement, so no effective treatment exists.

To improve outcome, two different SAA supplementation regimens have been proposed without consistent positive results, including methionine to prevent toxic accumulation of glycine by supplying single carbon groups [113-115] and tryptophan to counteract the effect of elevated brain glycine on the NMDA receptor $[116,117]$. In a single case of $\mathrm{NKH}$, tryptophan supplementation was reported to reduce hyperkinesia, explosive movements, and EEG abnormalities, as well as to improve verbal functioning and to increase the developmental quotient [116]. However, in another case of $\mathrm{NKH}$, no behavioural improvements could be demonstrated on tryptophan supplementation [117]. To conclude, methionine supplementation in $\mathrm{NKH}$ patients is probably not effective (level 5), while the reported effects of tryptophan supplementation are inconsistent (level 5).

\section{Discussion}

For most aminoacidopathies, dietary treatment includes natural protein restriction combined with a synthetic amino acid mixture devoid of the amino acids prior to the metabolic block or essential amino acid supplementation. Especially if the amino acid - that cannot be converted due to the enzymatic defect - is essential (e.g. phenylalanine in $\mathrm{PKU}$ ), dietary management has proven to be effective $[49,118,119]$. On the contrary, if the nonconvertible amino acid is nonessential (e.g. tyrosine in Tyrosinemia type I), dietary treatment is less effective $[120,121]$. The present review addresses the applications, objectives, and treatment effects of additional SAA supplementation for purposes other than to overcome a deficiency of the amino acid that has become essential by the enzymatic defect. Before discussing the main conclusions in further detail, we will first address some methodological issues.

In the present review, supplementation of one or two amino acids that have become essential by the enzymatic defect in aminoacidopathies (e.g. tyrosine in PKU, arginine in urea cycle defects) is not being addressed. Such SAA supplementation has been widely reported on already. Supplementation of more than two amino acids is not being discussed. Various combinations of large neutral amino acids - except for phenylalanine - have since long been suggested to serve different biochemical treatment objectives in PKU, as has already been reviewed by Van Spronsen et al. [122]. Research on this subject is still being performed [123], but a study investigating all hypothesized biochemical treatment objectives of large neutral amino acid supplementation in PKU is still hoped-for. More recently, BCAA supplementation for urea cycle defects treated with alternate pathway treatment (sodium phenylbutyrate or phenylacetate/benzoate) has been proposed [124-126] to prevent strongly decreased blood BCAA concentrations $[127,128]$ that have been shown to often precede metabolic decompensation [129]. Such supplementation is now being used in some clinics, but a beneficial effect has not been demonstrated yet [130]. The search strategy performed has been limited to articles written in English and German. Combined with the fact that especially rather dated articles could not all be obtained, this has posed the possibility of having missed some relevant articles.

The consideration of SAA supplementation in aminoacidopathies treated with natural protein restriction and synthetic amino acid mixtures is not always straightforward. First, treatment is not always based on comparable strategies. Even for one single aminoacidopathy, different SAA supplementation regimens can be considered, each with a different strategy. Also, a specific SAA supplementation regimen can be hypothesized to serve different strategies in one single aminoacidopathy. This complicates the formulation of uniform outcome measures.

Second, the need for SAA supplementation can either be posed directly by the disorder itself or secondary by its (dietary) treatment. If required due to dietary treatment, SAA supplementation mostly aims to restore a deficiency of specific amino acids. This seems to hold true especially for isoleucine. Of all amino acids, isoleucine has been found to be most critical for keratinocyte proliferation [23]. The importance of monitoring a deficiency of specific amino acids is exemplified in MMA, where low to very low concentrations of isoleucine and valine have been found to be widely present in patients, irrespective of the natural protein intake [25]. To restore specific amino acid deficiencies, three different challenges are experienced: 1 ) determining the minimal blood concentrations for individual amino acids; 2) monitoring amino acid levels; and 3) establishing optimal amino acid supplementation regimens.

The first challenge is especially applicable to HT1, as no data are available on the safe lower limits of blood phenylalanine concentrations. Theoretically, this can be an age-dependent parameter, related to velocity of (brain) development and growth.

Regarding the second challenge, careful monitoring of blood amino acid concentrations is crucial to timely detect deficiencies that are not yet clinically detectable, taking in mind that blood concentrations may not always reflect processes at a cellular level. Probably the most reliable method for detecting an amino acid deficiency is to determine whether the concentration of the specific 
amino acid either decreases (indicating that a deficiency is very likely), remains stable (indicating that a deficiency should be considered), or increases (indicating that a deficiency is unlikely) after a meal compared to the overnight fasting concentration [131]. Interpreting amino acid status can be particularly challenging if continuous tube feeding is given. Interpretation is further complicated by adherence issues. SAA are hard to administer (particularly in very small doses) and no studies address if patients actually consume them or take them in a way that utilization will be effective. Of course, an alternative strategy to detect amino acid deficiencies is the indicator amino acid oxidation method [8], but this method is used for research purposes rather than for clinical practice.

Regarding the third challenge, optimal treatment in response to deficiencies of offending precursor amino acids still remains to be investigated for most aminoacidopathies. Liberalization of dietary restrictions could prevent deficiencies of other essential nutrients besides amino acids, whereas, at the same time, it poses the risk of metabolic decompensation due to increased concentrations of other offending precursor amino acids. On the other hand, supplementation of SAA raises the question whether supplementation should be restricted to moments of measured deficiency or should be included in the daily amino acid mixtures.

Third, for many aminoacidopathies, evidence on the effects of SAA treatment is limited. The rarity of these disorders probably contributes in part to the fact that most evidence is restricted to case reports. Also, animal models, which allow for more invasive measurement and mechanism-based research, are not available for all disorders. However, even the data obtained from animal models are only to be used to some degree and, therefore, could not fully help us in this review to increase the level of evidence.

In conclusion, before application in routine clinical practice can be considered, for most SAA supplementation treatments in aminoacidopathies, further research is warranted, both in animal models and patients. It is the opinion of the authors that clinical research would first require measuring the need of the SAA to be supplemented in individual patients. If results show that for most patients, having the same disorder, the extra need of such amino acid is comparable, this could result in inclusion of the extra amount in the precursor-free amino acid mixtures or essential amino acid supplements. The arginine-enriched amino acid formula for GA-I or the isoleucine and valine enriched formula for acute MSUD management, as studied by Strauss et al., may be good examples $[42,49]$. To this purpose, well-designed clinical research is necessary with initially small and later on larger populations. Multi-center studies, possibly involving multiple countries, would be crucial in this regard.
The first treatment of inherited metabolic diseases was based on a change in nutritional intake, and this happened to be the first treatment ever of mental retardation. After that, many nutritional and medical interventions have been developed. Now, we might -again- enter a new era in which rather simple changes in nutritional intake may improve the outcome of patients with such devastating diseases. Such change may be elicited by supplementation of SAA, including both physiological and non-physiological amino acids, especially aiming at competition with toxic agents for entry into target organs (the brain in particular).

\section{Additional file}

Additional file 1: Suggested applications of SAA supplements in different aminoacidopathies treated with severe natural protein restriction and an amino acid mixture devoid of the offending precursor amino acids.

\section{Abbreviations}

ADMA: Asymmetric dimethylarginine; BCAA: Branched-chain amino acids; CBS: Cystathionine $\beta$-synthase; GA: Gyrate atrophy; GA-l: Glutaric aciduria type I; GAA: Guanidinoacetate; GAMT: Guanidinoacetate methyltransferase; HCU: Homocystinuria; HHH: Hyperammonaemia-hyperornithinaemiahomocitrullinuria; HT1: Hereditary tyrosinemia type I; IVA: Isovaleric acid; IVG: N-isovalerylglycine; LPI: Lysinuric protein intolerance; MMA: Methylmalonic acidemia; MSUD: Maple syrup urine disease; NO: Nitrogen oxide; NKH: Nonketotic hyperglycinemia; NTBC: 2-(2-nitro-4-trifluoromethylbenzyl)1,3-cyclohexanedione; OAT: Ornithine aminotransferase; PA: Propionic acidemia; PKU: Phenylketonuria; SAA: Single amino acid.

\section{Competing interests}

MvR has received grants, consultancy fees, and advisory board fees from Merck Serono and Nutricia Research, speaker's honoraria from Merck Serono, Nutricia Research, and Orphan Europe, and expert testimony fees from Merck Serono. FJvS has received research grants, advisory board fees, and speaker's honoraria from Merck Serono and Nutricia Research. AM has received research grants, advisory board fees, and speaker's honoraria from Merck Serono, Vitaflo International Ltd, and Nutricia Research. All other authors have declared not to have conflicts of interest.

\section{Authors' contributions}

FJVS, TGJD, and DVV were involved in the design of the systematic literature search. DVV performed the literature search and study selection, primarily supervised by FJVS and TGJD. DVV wrote the manuscript. FJvS and TGJD provided important contributions throughout the manuscript preparation process. MvR, MJdG, AM, and MRHF critically assessed the selected literature and made important contributions to the revision of the manuscript. All authors read and approved the final manuscript.

\section{Author details}

1Department of Metabolic Diseases, Beatrix Children's Hospital, University Medical Center Groningen, University of Groningen, Groningen, the Netherlands. Dietetic Department, Birmingham Children's Hospital, Birmingham, United Kingdom. ${ }^{3}$ Laboratory of Metabolic Diseases, Department of Laboratory Medicine, University Medical Center Groningen, University of Groningen, Groningen, the Netherlands.

Received: 28 November 2013 Accepted: 27 December 2013 Published: 13 January 2014

\section{References}

1. Rosenberg LE: Diagnosis and management of inherited aminoacidopathies in the newborn and the unborn. Clin Endocrinol Metab 1974, 3(1):145-152. 
2. Saudubray J, Sedel F, Walter JH: Clinical approach to treatable inborn metabolic diseases: An introduction. J Inherit Metab Dis 2006, 29(2-3):261-274.

3. Camp KM, Lloyd-Puryear MA, Huntington KL: Nutritional treatment for inborn errors of metabolism: indications, regulations, and availability of medical foods and dietary supplements using phenylketonuria as an example. Mol Genet Metab 2012, 107(1-2):3-9.

4. Walter $\mathrm{JH}, \mathrm{MacDonald} \mathrm{A}$ : The use of amino acid supplements in inherited metabolic disease. J Inherit Metab Dis 2006, 29(2-3):279-280.

5. Rouse BM: Phenylalanine deficiency syndrome. J Pediatr 1966, 69(2):246-249.

6. Blecker U, De Meirleir L, De Raeve L, Ramet J, Vandenplas Y: Acrodermatitislike syndrome in organic aciduria. Pediatrics 1994, 93(3):537.

7. Northrup H, Sigman ES, Hebert AA: Exfoliative erythroderma resulting from inadequate intake of branched-chain amino acids in infants with maple syrup urine disease. Arch Dermatol 1993, 129(3):384-385.

8. Elango R, Ball RO, Pencharz PB: Indicator amino acid oxidation: concept and application. J Nutr 2008, 138(2):243-246.

9. Millington DS, Roe CR, Maltby DA, Inoue F: Endogenous catabolism is the major source of toxic metabolites in isovaleric acidemia. J Pediatr 1987 , 110(1):56-60.

10. Krieger I, Tanaka K: Therapeutic effects of glycine in isovaleric acidemia. Pediatr Res 1976, 10(1):25-29.

11. Yudkoff M, Cohn RM, Puschak R, Rothman R, Segal S: Glycine therapy in isovaleric acidemia. J Pediatr 1978, 92(5):813-817.

12. Roe CR, Millington DS, Maltby DA, Kahler SG, Bohan TP: L-carnitine therapy in isovaleric acidemia. J Clin Invest 1984, 74(6):2290-2295.

13. Shigematsu Y, Sudo M, Momoi T, Inoue Y, Suzuki Y, Kameyama J: Changing plasma and urinary organic acid levels in a patient with isovaleric acidemia during an attack. Pediatr Res 1982, 16(9):771-775.

14. Velazquez A, Prieto EC: Glycine in acute management of isovalericacidaemia. Lancet 1980, 1(8163):313-314.

15. Cohn RM, Yudkoff M, Rothman R, Segal S: Isovaleric acidemia: use of glycine therapy in neonates. N Engl J Med 1978, 299(18):996-999.

16. Naglak M, Salvo R, Madsen K, Dembure P, Elsas L: The treatment of isovaleric acidemia with glycine supplement. Pediatr Res 1988, 24(1):9-13.

17. Chalmers RA, de Sousa C, Tracey BM, Stacey TE, Weaver C, Bradley D: Lcarnitine and glycine therapy in isovaleric acidaemia. $J$ Inherit Metab Dis 1985, 8(Suppl 2):141-142.

18. de Sousa C, Chalmers RA, Stacey TE, Tracey BM, Weaver CM, Bradley D: The response to $\mathrm{L}$-carnitine and glycine therapy in isovaleric acidaemia. Eur J Pediatr 1986, 144(5):451-456.

19. Berry GT, Yudkoff M, Segal S: Isovaleric acidemia: medical and neurodevelopmental effects of long-term therapy. J Pediatr 1988, 113(1 Pt 1):58-64.

20. Fries $M H$, Rinaldo $P$, Schmidt-Sommerfeld $E$, Jurecki $E$, Packman S: Isovaleric acidemia: response to a leucine load after three weeks of supplementation with glycine, L-carnitine, and combined glycine-carnitine therapy. J Pediatr 1996, 129(3):449-452.

21. Koopman RJ, Happle R: Cutaneous manifestations of methylmalonic acidemia. Arch Dermatol Res 1990, 282(4):272-273.

22. De Raeve L, De Meirleir L, Ramet J, Vandenplas Y, Gerlo E: Acrodermatitis enteropathica-like cutaneous lesions in organic aciduria. J Pediatr 1994, 124(3):416-420.

23. Shipley GD, Pittelkow MR: Control of growth and differentiation in vitro of human keratinocytes cultured in serum-free medium. Arch Dermatol 1987, 123(11):1541a-1544a.

24. Bosch AM, Sillevis Smitt JH, Van Gennip AH, Abeling NG, Schutgens RB, Bakker HD, Wijburg FA: latrogenic isolated isoleucine deficiency as the cause of an acrodermatitis enteropathica-like syndrome. $\mathrm{Br} J$ Dermato 1998, 139(3):488-491.

25. Touati G, Valayannopoulos V, Mention K, de Lonlay P, Jouvet P, Depondt E, Assoun M, Souberbielle JC, Rabier D, Ogier de Baulny H, Saudubray JM: Methylmalonic and propionic acidurias: management without or with a few supplements of specific amino acid mixture. J Inherit Metab Dis 2006, 29(2-3):288-298

26. Hauser NS, Manoli I, Graf JC, Sloan J, Venditti CP: Variable dietary management of methylmalonic acidemia: metabolic and energetic correlations. Am J Clin Nutr 2011, 93(1):47-56.

27. Yannicelli S: Nutrition therapy of organic acidaemias with amino acidbased formulas: emphasis on methylmalonic and propionic acidaemia. J Inherit Metab Dis 2006, 29(2-3):281-287.
28. Satoh T, Narisawa K, Tazawa Y, Suzuki H, Hayasaka K, Tada K, Kawakami T: Dietary therapy in a girl with propionic acidemia: supplement with leucine resulted in catch up growth. Tohoku J Exp Med 1983, 139(4):411-415.

29. Lane TN, Spraker MK, Parker SS: Propionic acidemia manifesting with low isoleucine generalized exfoliative dermatosis. Pediatr Dermatol 2007, 24(5):508-510.

30. Scholl-Burgi S, Sass JO, Zschocke J, Karall D: Amino acid metabolism in patients with propionic acidaemia. J Inherit Metab Dis 2012, 35(1):65-70.

31. Scholl-Burgi S, Sass JO, Heinz-Erian P, Amann E, Haberlandt E, Albrecht U, Ertl C, Sigl SB, Lagler F, Rostasy K, Karall D: Changes in plasma amino acid concentrations with increasing age in patients with propionic acidemia. Amino Acids 2010, 38(5):1473-1481.

32. North KN, Korson MS, Gopal YR, Rohr FJ, Brazelton TB, Waisbren SE, Warman ML: Neonatal-onset propionic acidemia: neurologic and developmental profiles, and implications for management. J Pediatr 1995, 126(6):916-922.

33. Al-Hassnan ZN, Boyadjiev SA, Praphanphoj V, Hamosh A, Braverman NE, Thomas GH, Geraghty MT: The relationship of plasma glutamine to ammonium and of glycine to acid-base balance in propionic acidaemia. J Inherit Metab Dis 2003, 26(1):89-91.

34. Roe CR, Bohan TP: L-carnitine therapy in propionicacidaemia. Lancet 1982 , 1(8286):1411-1412.

35. Kolker S, Christensen E, Leonard JV, Greenberg CR, Boneh A, Burlina AB, Burlina AP, Dixon M, Duran M, Garcia Cazorla A, Goodman SI, Koeller DM, Kyllerman M, Muhlhausen C, Muller E, Okun JG, Wilcken B, Hoffmann GF, Burgard P: Diagnosis and management of glutaric aciduria type I-revised recommendations. J Inherit Metab Dis 2011, 34(3):677-694.

36. Kolker S, Sauer SW, Okun JG, Hoffmann GF, Koeller DM: Lysine intake and neurotoxicity in glutaric aciduria type I: towards a rationale for therapy? Brain 2006, 129(Pt 8):e54.

37. Kolker S, Sauer SW, Surtees RA, Leonard JV: The aetiology of neurological complications of organic acidaemias-a role for the blood-brain barrier. J Inherit Metab Dis 2006, 29(6):701-704. discussion 705-6.

38. Sauer SW, Okun JG, Fricker G, Mahringer A, Muller I, Crnic LR, Muhlhausen C, Hoffmann GF, Horster F, Goodman SI, Harding CO, Koeller DM, Kolker S: Intracerebral accumulation of glutaric and 3-hydroxyglutaric acids secondary to limited flux across the blood-brain barrier constitute a biochemical risk factor for neurodegeneration in glutaryl-CoA dehydrogenase deficiency. J Neurochem 2006, 97(3):899-910.

39. Zinnanti WJ, Lazovic J: Mouse model of encephalopathy and novel treatment strategies with substrate competition in glutaric aciduria type I. Mol Genet Metab 2010, 100(Suppl 1):S88-S91.

40. Zinnanti WJ, Lazovic J, Housman C, LaNoue K, O'Callaghan JP, Simpson I, Woontner M, Goodman SI, Connor JR, Jacobs RE, Cheng KC: Mechanism of age-dependent susceptibility and novel treatment strategy in glutaric acidemia type I. J Clin Invest 2007, 117(11):3258-3270.

41. Sauer SW, Opp S, Hoffmann GF, Koeller DM, Okun JG, Kolker S: Therapeutic modulation of cerebral L-lysine metabolism in a mouse model for glutaric aciduria type I. Brain 2011, 134(Pt 1):157-170.

42. Strauss KA, Brumbaugh J, Duffy A, Wardley B, Robinson D, Hendrickson C, Tortorelli S, Moser AB, Puffenberger EG, Rider NL, Morton DH: Safety, efficacy and physiological actions of a lysine-free, arginine-rich formula to treat glutaryl-CoA dehydrogenase deficiency: focus on cerebral amino acid influx. Mol Genet Metab 2011, 104(1-2):93-106.

43. Kolker S, Boy SP, Heringer J, Muller E, Maier EM, Ensenauer R, Muhlhausen C, Schlune A, Greenberg CR, Koeller DM, Hoffmann GF, Haege G, Burgard P. Complementary dietary treatment using lysine-free, arginine-fortified amino acid supplements in glutaric aciduria type I - A decade of experience. Mol Genet Metab 2012, 107(1-2):72-80.

44. Morton DH, Strauss KA, Robinson DL, Puffenberger EG, Kelley RI: Diagnosis and treatment of maple syrup disease: a study of 36 patients. Pediatrics 2002, 109(6):999-1008.

45. Riazi R, Rafii M, Clarke JT, Wykes LJ, Ball RO, Pencharz PB: Total branchedchain amino acids requirement in patients with maple syrup urine disease by use of indicator amino acid oxidation with L-[1-13C]phenylalanine. Am J Physiol Endocrinol Metab 2004, 287(1):E142-E149.

46. Koch SE, Packman S, Koch TK, Williams ML: Dermatitis in treated maple syrup urine disease. J Am Acad Dermatol 1993, 28(2 Pt 2):289-292.

47. Giacoia GP, Berry GT: Acrodermatitis enteropathica-like syndrome secondary to isoleucine deficiency during treatment of maple syrup urine disease. Am J Dis Child 1993, 147(9):954-956. 
48. Thomas E: Dietary management of inborn errors of amino acid metabolism with protein-modified diets. J Child Neurol 1992, 7(Suppl):S92-S111.

49. Strauss KA, Wardley B, Robinson D, Hendrickson C, Rider NL, Puffenberger EG, Shellmer D, Moser AB, Morton DH: Classical maple syrup urine disease and brain development: principles of management and formula design. Mol Genet Metab 2010, 99(4):333-345.

50. Parini R, Sereni LP, Bagozzi DC, Corbetta C, Rabier D, Narcy C, Hubert P, Saudubray JM: Nasogastric drip feeding as the only treatment of neonatal maple syrup urine disease. Pediatrics 1993, 92(2):280-283.

51. Nyhan WL, Rice-Kelts M, Klein J, Barshop BA: Treatment of the acute crisis in maple syrup urine disease. Arch Pediatr Adolesc Med 1998, 152(6):593-598.

52. Zinnanti WJ, Lazovic J, Griffin K, Skvorak KJ, Paul HS, Homanics GE, Bewley MC, Cheng KC, Lanoue KF, Flanagan JM: Dual mechanism of brain injury and novel treatment strategy in maple syrup urine disease. Brain 2009, 132(Pt 4):903-918.

53. Tews JK, Repa JJ, Harper AE: Branched-chain and other amino acids in tissues of rats fed leucine-limiting amino acid diets containing norleucine. J Nutr 1991, 121(3):364-378.

54. Snyderman SE, Norton PM, Roitman E, Holt LEJ: Maple syrup urine disease, with particular reference to dietotherapy. Pediatrics 1964 , 34:454-472.

55. Bridi R, Araldi J, Sgarbi MB, Testa CG, Durigon K, Wajner M, Dutra-Filho CS. Induction of oxidative stress in rat brain by the metabolites accumulating in maple syrup urine disease. Int J Dev Neurosci 2003, 21(6):327-332.

56. Kasinski A, Doering CB, Danner DJ: Leucine toxicity in a neuronal cell model with inhibited branched chain amino acid catabolism. Brain Res Mol Brain Res 2004, 122(2):180-187.

57. Perry TL: Phenylketonuria and glutamine. N Engl I Med 1970, 282(26):1490.

58. Perry TL, Hansen S, Tischler B, Bunting R, Diamond S: Glutamine depletion in phenylketonuria. A possible cause of the mental defect. $N$ Engl J Med 1970, 282(14):761-766.

59. Meister A, Udenfriend S, Bessman SP: Diminished phenylketonuria in phenylpyruvic oligophrenia after administration of L-glutamine, L-glutamate or L-asparagine. J Clin Invest 1956, 35(6):619-626.

60. Hjelm M, Seakins J, Antoshechkin A: Indications of changed amino acid homeostasis in untreated and treated PKU. Acta Paediatr Supp/ 1994, 407:57-59.

61. Boehm G, Cervantes H, Georgi G, Jelinek J, Sawatzki G, Wermuth B, Colombo JP: Effect of increasing dietary threonine intakes on amino acid metabolism of the central nervous system and peripheral tissues in growing rats. Pediatr Res 1998, 44(6):900-906.

62. Sanjurjo P, Aldamiz L, Georgi G, Jelinek J, Ruiz Jl, Boehm G: Dietary threonine reduces plasma phenylalanine levels in patients with hyperphenylalaninemia. J Pediatr Gastroenterol Nutr 2003, 36(1):23-26.

63. Maenz DD, Patience JF: L-threonine transport in pig jejunal brush border membrane vesicles. Functional characterization of the unique system $B$ in the intestinal epithelium. J Biol Chem 1992, 267(31):22079-22086.

64. Poncet IB, Berry HK, Butcher RE, Kazmaier KJ: Biochemical effects of induced phenylketonuria in rats. Biol Neonate 1975, 26(1-2):88-101.

65. Airaksinen MM, Leppanen M, Turakka H, Marvola MM, MacDonald EJ: Protective effect of tryptophan and 5-hydroxytryptophan on experimental phenylketonuria induced with phenylalanine $+p$-cholorophenylalanine in rats. Med Biol 1975, 53(6):481-488.

66. Lou H: Large doses of tryptophan and tyrosine as potential therapeutic alternative to dietary phenylalanine restriction in phenylketonuria. Lancet 1985, 2(8447):150-151.

67. Vogel KR, Arning E, Wasek BL, Bottiglieri T, Gibson KM: Non-physiological amino acid (NPAA) therapy targeting brain phenylalanine reduction: pilot studies in PAH (ENU2) mice. J Inherit Metab Dis 2013, 36(3):513-523.

68. Basile-Filho A, El-Khoury AE, Beaumier L, Wang SY, Young VR: Continuous 24-h L-[1-13C]phenylalanine and L-[3,3-2H2]tyrosine oral-tracer studies at an intermediate phenylalanine intake to estimate requirements in adults. Am J Clin Nutr 1997, 65(2):473-488.

69. Sanchez M, El-Khoury AE, Castillo L, Chapman TE, Basile Filho A, Beaumier L, Young VR: Twenty-four-hour intravenous and oral tracer studies with L[1-13C]phenylalanine and $\mathrm{L}-[3,3-2 \mathrm{H} 2]$ tyrosine at a tyrosine-free, generous phenylalanine intake in adults. Am J Clin Nutr 1996, 63(4):532-545.

70. Wilson CJ, Van Wyk KG, Leonard JV, Clayton PT: Phenylalanine supplementation improves the phenylalanine profile in tyrosinaemia. J Inherit Metab Dis 2000, 23(7):677-683.
71. Daly A, Gokmen-Ozel H, MacDonald A, Preece MA, Davies P, Chakrapani A, McKiernan P: Diurnal variation of phenylalanine concentrations in tyrosinaemia type 1: should we be concerned? J Hum Nutr Diet 2012, 25(2):111-116

72. Alam SQ, Becker RV, Stucki WP, Rogers QR, Harper AE: Effect of threonine on the toxicity of excess tyrosine and cataract formation in the rat. J Nutr 1966, 89(1):91-96.

73. Alam SQ, Rogers QR, Harper AE: Effect of tyrosine and threonine on free amino acids in plasma, liver, muscle, and eye in the rat. J Nutr 1966, 89(1):97-105.

74. Datta K, Ghosh JJ: Effect of dietary threonine supplementation on tyrosine toxicity in the rat. J Nutr 1977, 107(9):1575-1582.

75. Lock EA, Gaskin P, Ellis MK, Robinson M, Provan WM, Smith LL: The effect of a low-protein diet and dietary supplementation of threonine on tyrosine and 2-(2-nitro-4-trifluoromethylbenzoyl) cyclohexane-1,3-dione-induced corneal lesions, the extent of tyrosinemia, and the activity of enzymes involved in tyrosine catabolism in the rat. Toxicol Appl Pharmacol 1998, 150(1):125-132.

76. Cleary MA, Dorland L, de Koning TJ, Poll-The BT, Duran M, Mandell R, Shih VE, Berger R, Olpin SE, Besley GT: Ornithine aminotransferase deficiency: diagnostic difficulties in neonatal presentation. J Inherit Metab Dis 2005, 28(5):673-679.

77. Peltola K, Heinonen OJ, Nanto-Salonen K, Pulkki K, Simell O: Oral lysine feeding in gyrate atrophy with hyperornithinaemia-a pilot study. J Inherit Metab Dis 2000, 23(4):305-307.

78. Elpeleg N, Korman SH: Sustained oral lysine supplementation in ornithine delta-aminotransferase deficiency. J Inherit Metab Dis 2001, 24(3):423-424.

79. Hayasaka S, Saito T, Nakajima H, Takahashi O, Mizuno K, Tada K: Clinical trials of vitamin $\mathrm{B} 6$ and proline supplementation for gyrate atrophy of the choroid and retina. Br J Ophthalmol 1985, 69(4):283-290.

80. Saito T, Omura K, Hayasaka S, Nakajima H, Mizuno K, Tada K Hyperornithinemia with gyrate atrophy of the choroid and retina: a disturbance in de novo formation of proline. Tohoku J Exp Med 1981, 135(4):395-402.

81. Hayasaka S, Shiono T, Takaku Y, Mizuno K: Ornithine ketoacid aminotransferase in the bovine eye. Invest Ophthalmol Vis Sci 1980 19(12):1457-1460.

82. Ueda M, Masu Y, Ando A, Maeda H, Del Monte MA, Uyama M, Ito S: Prevention of ornithine cytotoxicity by proline in human retinal pigment epithelial cells. Invest Ophthalmol Vis Sci 1998, 39(5):820-827.

83. Stockler S, Marescau B, De Deyn PP, Trijbels JM, Hanefeld F: Guanidino compounds in guanidinoacetate methyltransferase deficiency, a new inborn error of creatine synthesis. Metabolism 1997, 46(10):1189-1193.

84. Schulze A, Mayatepek E, Bachert P, Marescau B, De Deyn PP, Rating D: Therapeutic trial of arginine restriction in creatine deficiency syndrome. Eur J Pediatr 1998, 157(7):606-607.

85. Schulze A, Hoffmann GF, Bachert P, Kirsch S, Salomons GS, Verhoeven NM, Mayatepek E: Presymptomatic treatment of neonatal guanidinoacetate methyltransferase deficiency. Neurology 2006, 67(4):719-721.

86. Schulze A, Ebinger F, Rating D, Mayatepek E: Improving treatment of guanidinoacetate methyltransferase deficiency: reduction of guanidinoacetic acid in body fluids by arginine restriction and ornithine supplementation. Mol Genet Metab 2001, 74(4):413-419.

87. Mercimek-Mahmutoglu S, Dunbar M, Friesen A, Garret S, Hartnett C, Huh L, Sinclair G, Stockler S, Wellington S, Pouwels PJ, Salomons GS, Jakobs C: Evaluation of two year treatment outcome and limited impact of arginine restriction in a patient with GAMT deficiency. Mol Genet Metab 2012, 105(1):155-158.

88. Mercimek-Mahmutoglu S, Stoeckler-lpsiroglu S, Adami A, Appleton R, Araujo HC, Duran M, Ensenauer R, Fernandez-Alvarez E, Garcia P, Grolik C, Item CB, Leuzzi V, Marquardt I, Muhl A, Saelke-Kellermann RA, Salomons GS, Schulze A, Surtees R, van der Knaap MS, Vasconcelos R, Verhoeven NM, Vilarinho L, Wilichowski E, Jakobs C: GAMT deficiency: features, treatment, and outcome in an inborn error of creatine synthesis. Neurology 2006, 67(3):480-484.

89. Verbruggen KT, Sijens PE, Schulze A, Lunsing RJ, Jakobs C, Salomons GS, van Spronsen FJ: Successful treatment of a guanidinoacetate methyltransferase deficient patient: findings with relevance to treatment strategy and pathophysiology. Mol Genet Metab 2007, 91(3):294-296.

90. Kawakami Y, Ohuchi S, Morita T, Sugiyama K: Hypohomocysteinemic effect of cysteine is associated with increased plasma cysteine concentration 
in rats fed diets low in protein and methionine levels. J Nutr Sci Vitaminol (Tokyo) 2009, 55(1):66-74

91. Lee $\mathrm{PJ}$, Briddon $\mathrm{A}$ : A rationale for cystine supplementation in severe homocystinuria. J Inherit Metab Dis 2007, 30(1):35-38.

92. Sydow K, Schwedhelm E, Arakawa N, Bode-Boger SM, Tsikas D, Hornig B, Frolich JC, Boger RH: ADMA and oxidative stress are responsible for endothelial dysfunction in hyperhomocyst(e)inemia: effects of L-arginine and B vitamins. Cardiovasc Res 2003, 57(1):244-252

93. Cusworth DC, Gattereau A: Inhibition of renal tubular reabsorption of homocystine by lysine and arginine. Lancet 1968, 2(7574):916-917.

94. Simell O, Mackenzie S, Clow CL, Scriver CR: Ornithine loading did not prevent induced hyperammonemia in a patient with hyperornithinemiahyperammonemia-homocitrullinuria syndrome. Pediatr Res 1985 19(12):1283-1287.

95. Oyanagi K, Tsuchiyama A, Itakura Y, Sogawa H, Wagatsuma K, Nakao T, Sakamoto S, Yachi A: The mechanism of hyperammonaemia and hyperornithinaemia in the syndrome of hyperornithinaemia, hyperammonaemia with homocitrullinuria. J Inherit Metab Dis 1983, 6(3):133-134.

96. Fell V, Pollitt RJ, Sampson GA, Wright T: Ornithinemia, hyperammonemia, and homocitrullinuria. A disease associated with mental retardation and possibly caused by defective mitochondrial transport. Am J Dis Child 1974, 127(5):752-756.

97. Hayasaka S, Kodama T, Ohira A: Retinal risks of high-dose ornithine supplements: a review. Br J Nutr 2011, 106(6):801-811.

98. Dionisi Vici C, Bachmann C, Gambarara M, Colombo JP, Sabetta G: Hyperornithinemia-hyperammonemia-homocitrullinuria syndrome: low creatine excretion and effect of citrulline, arginine, or ornithine supplement. Pediatr Res 1987, 22(3):364-367.

99. Näntö-Salonen K, Simell OG: Transport defects of amino acids at the cell membrane: Cystinuria, Lysinuric protein intolerance and Hartnup disorder. In Inborn Metabolic Diseases. Diagnosis and Treatment 4th Edition. Edited by Fernandes J, Saudubray J, van den Berghe G, Walter JH. Heidelberg, Germany: Springer Medizin Verlag; 2006:324-326.

100. Rajantie J, Simell O, Perheentupa J: Oral administration of urea cycle intermediates in lysinuric protein intolerance: effect on plasma and urinary arginine and ornithine. Metabolism 1983, 32(1):49-51.

101. Mizutani N, Kato T, Maehara M, Watanabe K, Ban M: Oral administration of arginine and citrulline in the treatment of lysinuric protein intolerance. Tohoku J Exp Med 1984, 142(1):15-24.

102. Rajantie J: Orotic aciduria in lysinuric protein intolerance: dependence on the urea cycle intermediates. Pediatr Res 1981, 15(2):115-119.

103. Carpenter TO, Levy HL, Holtrop ME, Shih VE, Anast CS: Lysinuric protein intolerance presenting as childhood osteoporosis. Clinical and skeletal response to citrulline therapy. N Engl J Med 1985, 312(5):290-294.

104. Rajantie J, Simell O, Rapola J, Perheentupa J: Lysinuric protein intolerance: a two-year trial of dietary supplementation therapy with citrulline and lysine. J Pediatr 1980, 97(6):927-932

105. Kekomaki M, Visakorpi JK, Perheentupa J, Saxen L: Familial protein intolerance with deficient transport of basic amino acids. An analysis of 10 patients. Acta Paediatr Scand 1967, 56(6):617-630.

106. Goto I, Yoshimura T, Kuroiwa Y: Growth hormone studies in lysinuric protein intolerance. Eur J Pediatr 1984, 141(4):240-242.

107. Awrich AE, Stackhouse WJ, Cantrell JE, Patterson JH, Rudman D: Hyperdibasicaminoaciduria, hyperammonemia, and growth retardation: Treatment with arginine, lysine, and citrulline. J Pediatr 1975, 87(5):731-738

108. Lukkarinen M, Nanto-Salonen K, Pulkki K, Aalto M, Simell O: Oral supplementation corrects plasma lysine concentrations in lysinuric protein intolerance. Metabolism 2003, 52(7):935-938.

109. Lukkarinen M, Nanto-Salonen K, Pulkki K, Mattila K, Simell O: Effect of lysine infusion on urea cycle in lysinuric protein intolerance. Metabolism 2000, 49(5):621-625

110. Tanner LM, Nanto-Salonen K, Niinikoski H, Huoponen K, Simell O: Long-term oral lysine supplementation in lysinuric protein intolerance. Metabolism 2007, 56(2):185-189.

111. Rajantie J, Simell O, Perheentupa J: Oral administration of epsilon Nacetyllysine and homocitrulline in lysinuric protein intolerance. J Pediatr 1983, 102(3):388-390.

112. Oyanagi $K$, Sogawa $H$, Minami R, Nakao T, Chiba T: The mechanism of hyperammonemia in congenital lysinuria. J Pediatr 1979, 94(2):255-257.
113. De Groot CJ, Troelstra JA, Hommes FA: Nonketotic hyperglycinemia: an in vitro study of the glycine-serine conversion in liver of three patients and the effect of dietary methionine. Pediatr Res 1970, 4(3):238-243.

114. Trijbels JM, Monnens LA, van der Zee SP, Vrenken JA, Sengers RC, Schretlen ED: A patient with nonketotic hyperglycinemia: biochemical findings and therapeutic approaches. Pediatr Res 1974, 8(5):598-605.

115. Koepp P, de Groot CJ, Gruttner R, Rybak FC: Clinical findings and therapeutic problems in nonketotic hyperglycinemia. Monatsschr Kinderheilkd 1973, 121(7):401-403

116. Matsuo S, Inoue F, Takeuchi Y, Yoshioka H, Kinugasa A, Sawada T: Efficacy of tryptophan for the treatment of nonketotic hyperglycinemia: a new therapeutic approach for modulating the $\mathrm{N}$-methyl-D-aspartate receptor. Pediatrics 1995, 95(1):142-146.

117. Wiltshire EJ, Poplawski NK, Harrison JR, Fletcher JM: Treatment of late-onset nonketotic hyperglycinaemia: effectiveness of imipramine and benzoate. $J$ Inherit Metab Dis 2000, 23(1):15-21.

118. Mitchell JJ, Trakadis YJ, Scriver CR: Phenylalanine hydroxylase deficiency. Genet Med 2011, 13(8):697-707.

119. Komrower GM, Lambert AM, Cusworth DC, Westall RG: Dietary treatment of homocystinuria. Arch Dis Child 1966, 41(220):666-671.

120. van Spronsen FJ, Thomasse Y, Smit GP, Leonard JV, Clayton PT, Fidler V, Berger R, Heymans HS: Hereditary tyrosinemia type I: a new clinical classification with difference in prognosis on dietary treatment. Hepatology 1994, 20(5):1187-1191.

121. van Spronsen FJ, Smit GP, Wijburg FA, Thomasse Y, Visser G, Heymans HS: Tyrosinaemia type I: considerations of treatment strategy and experiences with risk assessment, diet and transplantation. J Inherit Metab Dis 1995, 18(2):111-114.

122. van Spronsen FJ, de Groot MJ, Hoeksma M, Reijngoud DJ, van Rijn M: Large neutral amino acids in the treatment of PKU: from theory to practice. J Inherit Metab Dis 2010, 33(6):671-676.

123. Yano S, Moseley K, Azen C: Large neutral amino acid supplementation increases melatonin synthesis in phenylketonuria: a new biomarker. J Pediatr 2012, 162(5):999-1003

124. Scaglia F: New insights in nutritional management and amino acid supplementation in urea cycle disorders. Mol Genet Metab 2010, 100(Suppl 1):S72-S76.

125. Wilcken B: Problems in the management of urea cycle disorders. Mol Genet Metab 2004, 81(Suppl 1):S86-S91.

126. Singh RH: Nutritional management of patients with urea cycle disorders. J Inherit Metab Dis 2007, 30(6):880-887.

127. Scaglia F, Carter S, O'Brien WE, Lee B: Effect of alternative pathway therapy on branched chain amino acid metabolism in urea cycle disorder patients. Mol Genet Metab 2004, 81(Suppl 1):S79-S85.

128. Tuchman M, Lee B, Lichter-Konecki U, Summar ML, Yudkoff M, Cederbaum SD, Kerr DS, Diaz GA, Seashore MR, Lee HS, McCarter RJ, Krischer JP, Batshaw ML, Urea Cycle Disorders Consortium of the Rare Diseases Clinical Research Network: Cross-sectional multicenter study of patients with urea cycle disorders in the United States. Mol Genet Metab 2008, 94(4):397-402.

129. Lee B, Singh RH, Rhead WJ, Sniderman King L, Smith W, Summar ML: Considerations in the difficult-to-manage urea cycle disorder patient. Crit Care Clin 2005, 21(4 Suppl):S19-S25.

130. Marini JC, Lanpher BC, Scaglia F, O'Brien WE, Sun Q, Garlick PJ, Jahoor F, Lee $B$ : Phenylbutyrate improves nitrogen disposal via an alternative pathway without eliciting an increase in protein breakdown and catabolism in control and ornithine transcarbamylase-deficient patients. Am J Clin Nutr 2011, 93(6):1248-1254.

131. Ozalp I, Young VR, Nagchaudhuri J, Tontisirin K, Scrimshaw NS: Plasma amino acid response in young men given diets devoid of single essential amino acids. J Nutr 1972, 102(9):1147-1158.

doi:10.1186/1750-1172-9-7

Cite this article as: van Vliet et al: Single amino acid supplementation in aminoacidopathies: a systematic review. Orphanet Journal of Rare Diseases 2014 9:7. 